\title{
Simulation-Based Optimization of Cure Cycle of Large Area Compression Molding for LED Silicone Lens
}

\author{
Min-Jae Song, ${ }^{1,2}$ Kwon-Hee Kim, ${ }^{2}$ Seok-Kwan Hong, ${ }^{1}$ \\ Jeong-Won Lee, ${ }^{1}$ Jeong-Yeon Park, ${ }^{1}$ Gil-Sang Yoon, ${ }^{1}$ and Heung-Kyu Kim ${ }^{3}$ \\ ${ }^{1}$ Molds \& Dies Technology R\&BD Group, Korea Institute of Industrial Technology, 7-47 Songdo-dong, Yeonsu-gu, \\ Incheon 406-840, Republic of Korea \\ ${ }_{2}^{2}$ Department of Mechanical Engineering, Korea University, Anam-dong, Seongbuk-gu, Seoul 136-713, Republic of Korea \\ ${ }^{3}$ Department of Automotive Engineering, Kookmin University, 77 Jeongneung-ro, Seongbuk-gu, Seoul 136-702, Republic of Korea
}

Correspondence should be addressed to Heung-Kyu Kim; krystal@kookmin.ac.kr

Received 5 December 2014; Revised 4 June 2015; Accepted 9 June 2015

Academic Editor: Liyuan Sheng

Copyright (c) 2015 Min-Jae Song et al. This is an open access article distributed under the Creative Commons Attribution License, which permits unrestricted use, distribution, and reproduction in any medium, provided the original work is properly cited.

\begin{abstract}
Three-dimensional heat transfer-curing simulation was performed for the curing process by introducing a large area compression molding for simultaneous forming and mass production for the lens and encapsulants in the LED molding process. A dynamic cure kinetics model for the silicone resin was adopted and cure model and analysis result were validated and compared through a temperature measurement experiment for cylinder geometry with cure model. The temperature deviation between each lens cavity could be reduced by implementing a simulation model on the large area compression mold and by optimizing the location of heat source. A two-step cure cycle was constructed to reduce excessive reaction peak at the initial stage and cycle time. An optimum cure cycle that could reduce cycle time by more than $29 \%$ compared to a one-step cure cycle by adjusting dwell temperature, heating rate, and dwell time was proposed. It was thus confirmed that an optimization of large area LED lens molding process was possible by using the present experiment and the finite element method.
\end{abstract}

\section{Introduction}

LED has the merits of semipermanent life, low power consumption, safety, and environment friendliness. With these merits, LED has rapidly replaced existing light sources recently. As a material of encapsulant for the protection of chip and lens for the light distribution of this LED, transparent polymer is mainly used. The molding process for LED packaging to produce this LED lens and encapsulant is largely divided into cast molding, injection molding, transfer molding, and compression molding. Among these, compression molding is the most suitable for mass production and simple method [1]. It is a mass production method dispensing resin into a lower mold compressed by an upper mold onto which LED lead frame is attached. The merit of this process is an optimum resin usage efficiency of more than $95 \%$, possible simultaneous forming of large numbers of encapsulants and lenses, and less damage in the LED chip and board due to low pressure forming. Therefore, it is one of the most cost-effective production methods with high efficiency (Figure 1).

Generally, a transparent thermoset resin such as epoxy or silicone resin is used for the encapsulant and lens for LED. However, epoxy which has been widely used has problems of impairing optical transmittance and yellowing at high temperature, making it difficult for practical implementation. While silicone resin, having excellent thermal and optical property compared with epoxy, is suitable for high-power LED requiring heat resistance and durability, its usage is being expanded to serve as backlight for large-sized LCD, UV lamp, and general lighting.

Silicone resin is manufactured through a process in which liquid-phase base and curing agent are mixed and input into mold and then cured by heat followed by cooling. However, abrupt temperature increase in the resin by excessive chemical reaction during curing leads to surface roughening, delamination from LED chip, residual void and moisture, and residual stress, resulting in the impairment of the mechanical 


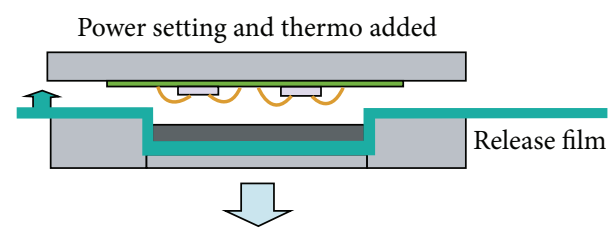

Dipping components in melted resin
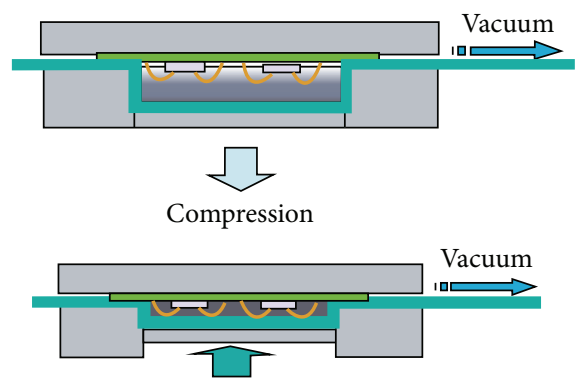

FIGURE 1: Compression molding process for LED molding [1].

and optical properties of LED product [2]. Therefore, a numerical simulation is tried to forecast abrupt temperature increases during the curing process and it has been applied as a means of optimal cure cycle [3-5]. However, research about cure simulation for silicone resin is lacking. The main focus in the related studies is on the epoxy among thermoset resins.

Loos and Springer [6] have analyzed a cure process for the two-dimensional composite flat-plate using an implicit finite difference method. Kim et al. [7] performed a onedimensional analysis for prepreg composite using an explicit finite difference method and proposed a model that restricted excessive temperature increases inside a composite during curing process. Bogetti and Gillespie [8] have performed a one-dimensional and two-dimensional heat transfer and cure simulation for a thick composite using an implicit finite difference method. Heat conduction equations coupled to the cure kinetics of the resin were used in their simulation. Guo et al. [9] have carried out a one-dimensional transient heat transfer for the autoclave cycle of the thick carbon fiber/epoxy material using a commercial finite element program. They concluded that conventional cure cycle had to be modified to prevent excessive temperature increase. Cheung et al. [10] have performed thermokinetic three-dimensional finite element analysis which combined heat transfer and cure simulation for the liquid composite molding process. They compared simulation and experiment using a simple flatplate while the degree of cure and temperature distribution was estimated for the thick, curved-shaped part. Hojjati and Hoa [11] performed analysis by coupling one-dimensional heat transfer, cure, and viscosity for a thick thermosetting composite. Rouison et al. [12] studied one-dimensional cure simulation for the RTM process with a natural fiber reinforced composite. They carried out simulation considering the heat conductivity and heat capacity changes during cure process and raised the accuracy of estimation by comparing the results with those by experiments. Kasza et al. [13] improved the accuracy of estimation in the cure kinetics model by considering a buoyancy flow during liquid phase and by carrying out a sensitivity analysis for a large epoxy sample having axis-symmetry. Liu et al. [14] performed threedimensional finite element analysis by proposing a chemothermo-microwave curing model for the microwave cure epoxy in the flip chip packaging process. Behzad and Sain [15] conducted a three-dimensional heat transfer finite element analysis for the natural fiber reinforced composite. First, they analyzed a simple block model and validated the model by comparing it with experimental results. Additional analysis was carried out for a complicatedly shaped automotive mirror case. They forecasted temperature distribution and degree of cure. Shojaei et al. [16] have performed three-dimensional control volume/finite element analysis for simulation of filling and cure for the resin transfer molding process meant for the composite having a thick and complicated shape. Joshi et al. [17] have performed a finite element analysis for the cure process for one-, two-, and three-dimensional shapes of fiber reinforced composite and validated the results by comparing them with those by experiment. Sekula et al. [18] performed a three-dimensional finite element analysis for the fill and curing process for epoxy which was being used in the products for high voltage insulation. They validated the simulation results with experimental results through a simple cylindrical test. After the simulation for the industrial application example, they analyzed the degree of cure for the product during the process. Yi et al. [19] performed a threedimensional finite element analysis for thermosetting the matrix composites and studied temperature distribution and degree of cure which became changed according to time step and boundary condition. Park et al. [20] performed a threedimensional finite element analysis for the thick composite structure and validated the results with experimental results and two-dimensional analysis results. Choi et al. [21] have performed three-dimensional finite element analysis of the curing process for the hat-shaped material in the resin transfer molding process. They also analyzed temperature distribution and degree of cure by introducing a two-step cure cycle.

In the earlier studies, residual stress was simulated in the cure process for the silicone resin of simple cylindrical LED encapsulation [2]. In this study, three-dimensional heat transfer-cure simulation was performed for the large area compression molding process to simultaneously form silicone resin lenses and encapsulants for LED. A dynamic cure kinetics model for silicone resin was proposed and the simulation results were validated through a temperature measurement experiment for the simple cylindrical shape. Further, heat source position was optimized after the simulation of model for a large area mold having $10 \times 5$ cavities to reduce temperature distribution between each cavity. Further, an optimum cure cycle was investigated by constructing a two-step cure cycle to reduce abrupt reaction peak at the initial stage and to reduce molding cycle time.

\section{Formulation}

2.1. Governing Equation and Cure Kinetics. The temperature solution is based on Fourier's heat conduction equation and the exothermic heat of the curing reaction source term. 
By neglecting the energy transfer by convection, the energy solution for three-dimensional heat conduction can be expressed as follows $[15,17,18,20-23]$ :

$$
\rho C_{p} \frac{\partial T}{\partial t}=k\left(\frac{\partial^{2} T}{\partial x^{2}}+\frac{\partial^{2} T}{\partial y^{2}}+\frac{\partial^{2} T}{\partial z^{2}}\right)+\rho H_{r} \frac{d \alpha}{d t} .
$$

Here, $T$ is the temperature, $k$ is the thermal conductivity, $C_{p}$ is the specific heat, $\rho$ is the density, $H_{r}$ is the total heat of reaction, $\alpha$ is the degree of cure, and $d \alpha / d t$ is the rate of reaction.

The amount of heat liberated by the reaction is usually taken as a measure of the degree of cure, assuming that the fractional conversion is proportional to the number of bonds formed in linking the chains together and that each bond releases the same amount of heat. Thus, the fraction conversion, also called a degree of cure, can be defined as follows:

$$
\alpha=\frac{H}{H_{r}} .
$$

In this equation, $H_{r}$ is the total heat of reaction and $H$ is the amount of heat release up to the current time which can be defined by the following:

$$
H=\int_{0}^{\tau} \dot{H} d t
$$

The degree of cure or conversion $(\alpha)$ equals zero when there has been no reaction, and it equals 1 when the reaction is complete. Thus, the cure is a field quantity that varies in space and time. The rate of heat generated during curing can be expressed as follows:

$$
\frac{d \alpha}{d t}=\frac{1}{H_{r}} \cdot \frac{d H}{d t}
$$

Here, $d \alpha / d t$ is the time rate of change in the degree of cure represented by an empirical model such as the one proposed by Kamal and Sourour [24]. For stepwise isothermal cure of a thermoset resin, the cure rate equation has the form of the following equation:

$$
\frac{d \alpha}{d t}=k \alpha^{m}(1-\alpha)^{n}
$$

Here, $\alpha=0$ at $t=0, m$ and $n$ are the constants, and the term $k$ contains the temperature dependence of the curing rate as follows:

$$
k=A \exp \left(-\frac{E}{R T}\right)
$$

Meanwhile, $A$ is the preexponential factor, $E$ is the activation energy, $T$ is the absolute temperature, and $R$ is the universal gas constant.

The most commonly used method among empirical methods to experimentally obtain the cure characteristics by measuring exothermic heat during cure process is a test using Differential Scanning Calorimeter (DSC). DSC

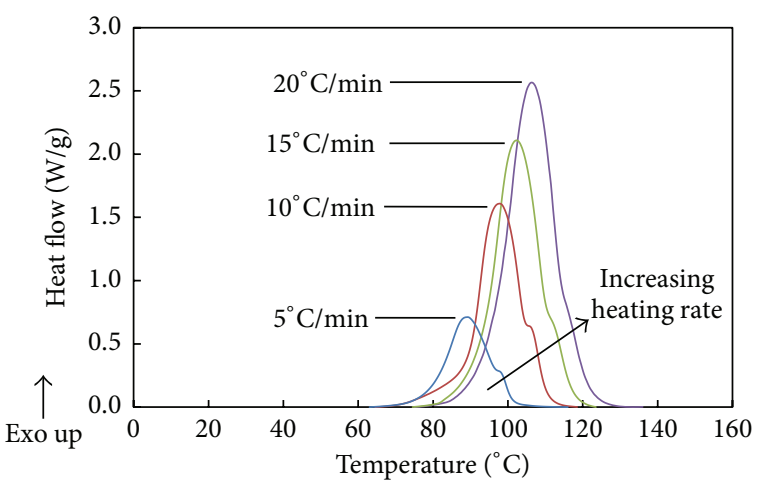

FIGURE 2: DSC exothermic curves of silicone.

measurement method is further divided into dynamic DSC which measures heat capacity after increasing temperature at constant speed and isothermal DSC method wherein heat capacity is measured while maintaining temperature fixed the same as that of DSC. Initial reaction is highly important in isothermal DSC method. However, silicone which has been used in the present study had a problem of containing errors after having many data as initial reaction because the reaction was already started in the course of temperature increase from room temperature to reaction temperature. It would be better to measure heat capacity from this kind of fast curing resin by dynamic method rather than isothermal condition. However, dynamic method would not give an idea about the relation among three components since three components, namely, conversion from liquid to solid, rate of cure, and temperature, are simultaneously changed. Also it requires difficult advanced curve fit skills [25].

Further, as cure progressed, glass transition temperature of the resin was increased. However, if glass transition temperature was increased higher than cure temperature, and the cured materials were changed from rubbery to glassy, reaction was converted to diffusion-controlled, resulting in significantly slow reaction rate [26]. Though this diffusioncontrolled effect was not prominent in the dynamic method compared to the isothermal method since the glass transition temperature of silicone resin used in the present study was $35^{\circ} \mathrm{C}$, which was far lower than that of the cure temperature, the reaction speed by diffusion was not considered in this study.

In this study, heating rates were fixed as four types and dynamic cure kinetics that can determine degree of cure, while cure rate was introduced [27-29]. DSC Q100 from TA Instrument was used as DSC, and an experiment was conducted with the sample container under nitrogen atmosphere inside an aluminum hermetic pan. Heating rates were calculated from four zones of $5,10,15$, and $20^{\circ} \mathrm{C} / \mathrm{min}$. Figure 2 shows the measured reaction heat capacity.

Autocatalyzed cure kinetics were applied as in (5) based on the above experimental results. However, (5) is isothermal reaction kinetics; thus, it becomes the same as (7) if this is converted to a dynamic reaction equation:

$$
\frac{d \alpha}{d T}=\frac{1}{\beta} k \alpha^{m}(1-\alpha)^{n}
$$






FIgURE 3: Comparison of the degree of cure between measurement and cure kinetics model.

TABLE 1: Constant of cure kinetics for silicone.

\begin{tabular}{lc}
\hline Parameter & Value \\
\hline$A\left(\mathrm{~S}^{-1}\right)$ & $6.6 e+9$ \\
$E(\mathrm{KJ} / \mathrm{Mol})$ & 85.461 \\
$m$ & 0.4 \\
$n$ & 1.9 \\
$R(\mathrm{~J} / \mathrm{mol} \cdot \mathrm{K})$ & 8.31 \\
$H_{r}(\mathrm{~J} / \mathrm{kg})$ & 145,298 \\
\hline
\end{tabular}

Here, $\beta$ is the DSC heating rate $d T / d t$.

Activation energy $E$ was obtained by applying Kissinger equation as in (4), wherein activation energy could be obtained at the maximum reaction rate point under constant heating rate [16]:

$$
-\ln \left(\frac{\beta}{T_{p}^{2}}\right)=\frac{E}{R T}-\ln \left(\frac{A R}{E}\right) .
$$

In this formula, $T_{p}^{2}$ is the maximum exothermic temperature.

Table 1 shows the constants of the obtained reaction equation. In Figure 3, experimental results and curve-fitting reaction equation are compared. As can be seen from the figure, the reaction equation relatively and exactly expresses the experimental results.

2.2. Thermal Properties. Thermal properties of silicone resin undergo changes according to temperature and degree of cure (conversion from liquid state to solid state) in the course of cure. In order to investigate these changes of thermal properties of the silicone resin, density, specific heat, and thermal conductivity were measured for the liquid resin before cure and cured solid resin.

A gravity bottle was used to measure the liquid resin, while a densimeter was used to measure the density of the solid resin. Meanwhile, thermal conductivity was measured with a laser flash for the two liquid zones $\left(25^{\circ} \mathrm{C}, 50^{\circ} \mathrm{C}\right)$ as well
TABLE 2: Thermal properties of silicone resin.

\begin{tabular}{ccccc}
\hline \multirow{2}{*}{ Liquid } & $\begin{array}{c}\text { Temp. } \\
{ }^{\circ} \mathrm{C}\end{array}$ & $\begin{array}{c}\text { Density } \\
\left(\mathrm{kg} / \mathrm{m}^{3}\right)\end{array}$ & $\begin{array}{c}\text { Thermal conductivity } \\
\left(\mathrm{W} / \mathrm{m} /{ }^{\circ} \mathrm{C}\right)\end{array}$ & $\begin{array}{c}\text { Specific heat } \\
\left(\mathrm{J} / \mathrm{kg} /{ }^{\circ} \mathrm{C}\right)\end{array}$ \\
\hline \multirow{3}{*}{ Solid } & 25 & \multirow{2}{*}{1150} & 0.213 & 1510 \\
& 50 & & 0.210 & 1547 \\
& 25 & & 0.151 & 1336 \\
& 150 & \multirow{2}{*}{1185} & 0.154 & 1455 \\
& & 0.156 & 1597 \\
\hline
\end{tabular}

as the three solid zones $\left(25^{\circ} \mathrm{C}, 80^{\circ} \mathrm{C}\right.$, and $\left.150^{\circ} \mathrm{C}\right)$. The specific heat was measured at temperature rise at a rate of $10^{\circ} \mathrm{C} / \mathrm{min}$ for the liquid state and solid state of the resin using a DSC. The changes of specific heat were measured with a standard sample sapphire. The measurement results are arranged in Table 2.

Changes of density at solid and liquid states of the silicone resin can be referred to as cure shrinkage [30] and it has a linear relationship with the general degree of cure [31]. Therefore, this change is expressed as a function for the degree of cure as shown below:

$$
\rho=24 \alpha+1144
$$

Changes in the thermal conductivity were large at liquid state and solid state of the resin, but it was not greatly changed by the temperature. Therefore, thermal conductivity was expressed only in terms of degree of cure as seen below. The zone of degree of cure $0.5-0.6$ is a gel point at which the silicone resin was changed from liquid state to solid state:

$$
k \begin{cases}0 \leq \alpha<0.5 ; & 0.211 \\ 0.5 \leq \alpha<0.6 ; & -0.482 \alpha+0.4425 \\ 0.6 \leq \alpha \leq 1.0 ; & 0.153\end{cases}
$$

The changes in the specific heat are expressed as a function of temperature and degree of cure as shown below [32]. In the equation, $C_{p_{0}}$ is the specific heat of the liquid resin, while $C_{p 1}$ is the specific heat of the cured resin:

$$
\begin{gathered}
C_{p}(\alpha, T)=C_{p_{0}}(T)(1-\alpha)+C_{p_{1}}(T) \alpha, \\
C_{p_{0}}(T)=1.8038 \times 10^{-3} T+0.9711, \\
C_{p_{1}}(T)=2.0151 \times 10^{-3} T+0.7385 .
\end{gathered}
$$

\section{Validation}

A simple experimental setup was constructed as shown in Figure 4 in order to compare and validate finite element analysis results with the experiment. Silicone resin was dosed with cylindrical aluminum mold $30 \mathrm{~mm}$ in diameter and $20 \mathrm{~mm}$ in height and this cylindrical resin underwent thermal curing. Mold was placed on the heating plate and it was heated at a rate of $15^{\circ} \mathrm{C} / \mathrm{min}$ from the initial stage, while the temperature was maintained at $130^{\circ} \mathrm{C}$ for one hour. A glass chamber was added above the mold to prevent heat loss 


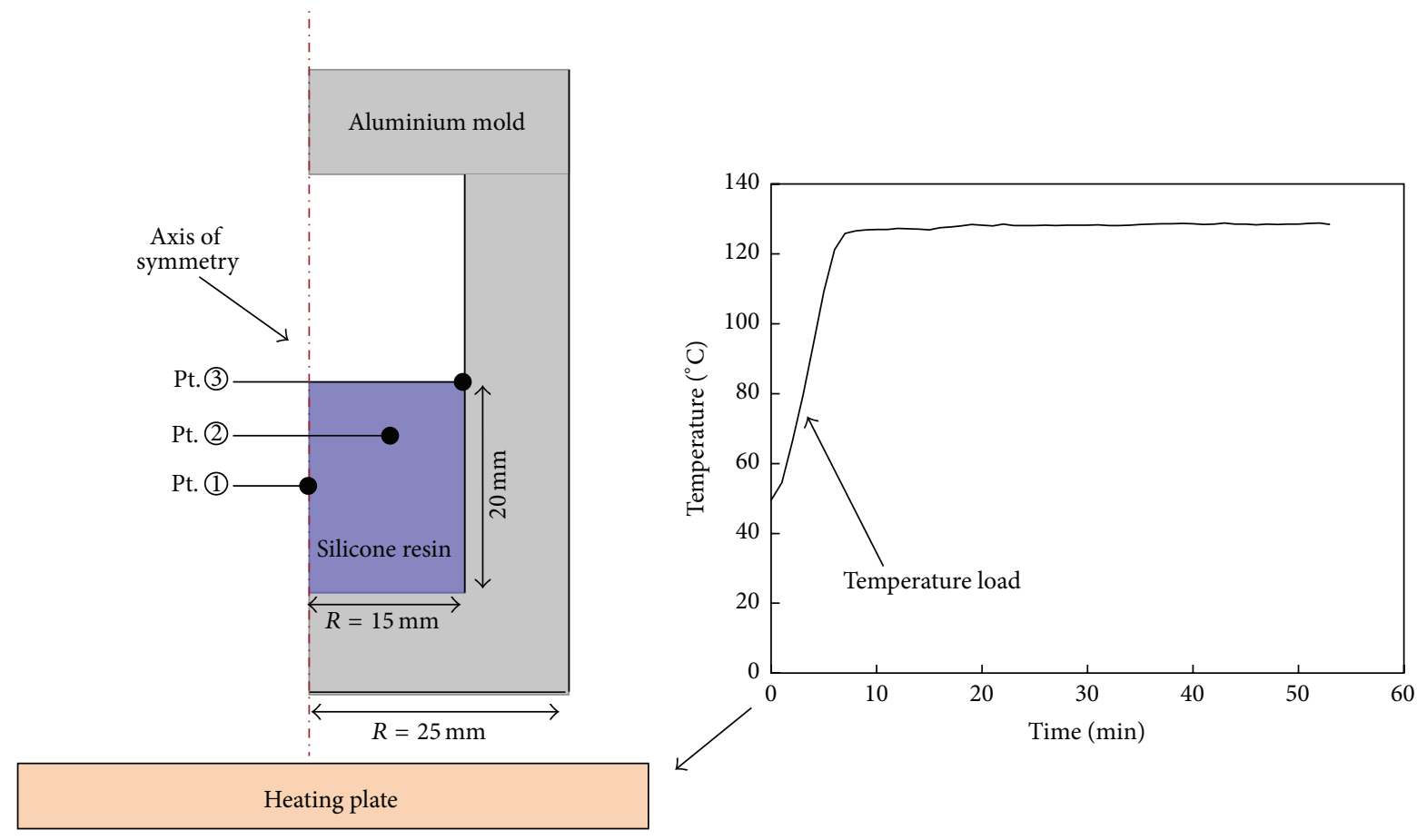

FIGURE 4: Experimental setup for silicone molding.

by outer atmosphere in order to raise the accuracy of the experiment. Thermocouples were inserted into the silicone, and mold and temperature were measured at real time using data acquisition (DAQ) device. Obtained temperature data were stored.

Figure 5(a) shows the comparison result of measured temperature distribution results (3 points) and analysis results. After around eight minutes, a maximum reaction peak of $164^{\circ} \mathrm{C}$ occurred as an active cure reaction at center point 1 . At point 2, a reaction peak lower than that was generated. Meanwhile, a reaction peak at point 3 at the adjourning mold wall did not occur; rather, temperature at point 3 displayed mold temperature profile as such. The analysis results as shown in Figure 5(b) showed that resin temperature increased from mold wall, and the largest reaction heat was generated near the center of resin due to the chemical reaction of resin when cure reaction became active. Though there was little difference from the experimental results, temperature distribution relatively followed the experimental results.

\section{Application of Large Area Compression Molding}

This simulation model was applied in the large area LED lens compression molding which could be implemented in the actual site. Figure 6 shows a large area LED lens mold used during simulation. Figure 6(a) displays a layout comprised of upper mold, lower mold, silicone resin, lead frame, and cartridge heater. Meanwhile, Figure 6(b) shows the lower mold to perform simulation. The lower mold was arranged as
$5 \times 10$ rows by selecting a semispherical type LED lens model with a total of 50 cavities. Heating for thermal cure, nine in number, having a diameter of $6 \mathrm{~mm}$, was arranged in series with a $10 \mathrm{~mm}$ gap.

Modeling was done with lower mold and silicone as shown in Figure 7. All the rest of the parts were arranged as boundary condition. Cartridge heater was set to $130^{\circ} \mathrm{C}$, while heat transfer coefficient $1000 \mathrm{~W} / \mathrm{m}^{2}$ was applied on the surface of hole where cartridge heater was installed. The surface, except the position where the heater was installed, was set with the insulation and initial temperature of mold and silicone resin set to $50^{\circ} \mathrm{C}$.

4.1. Optimization of Heater Location. Figure 8(b) shows temperature distribution according to mold location when an object is heated at an isothermal temperature of $130^{\circ} \mathrm{C}$. Since the mold had a $1 / 4$ symmetric geometry, temperature profile was observed from three points as shown in Figure 8(a). Mold temperature was observed by selecting the exact center of the mold. Simulation results yielded exothermic reaction as shown in Figure 8(b); that is, the reaction peak of temperature at $162^{\circ} \mathrm{C}$ was observed at 127 seconds from the center part point 1 , while a temperature of $159^{\circ} \mathrm{C}$ was observed from point 2 after $134 \mathrm{sec}$. The corner reaction peak of temperature $152^{\circ} \mathrm{C}$ after $164 \mathrm{sec}$ was observed from point 3 . It was judged that heat energy was not transmitted because heater was not arranged evenly compared with other locations. A maximum temperature difference of $10^{\circ} \mathrm{C}$ was observed according to location. Precise temperature control is important because it affects the physical and mechanical properties of cured 


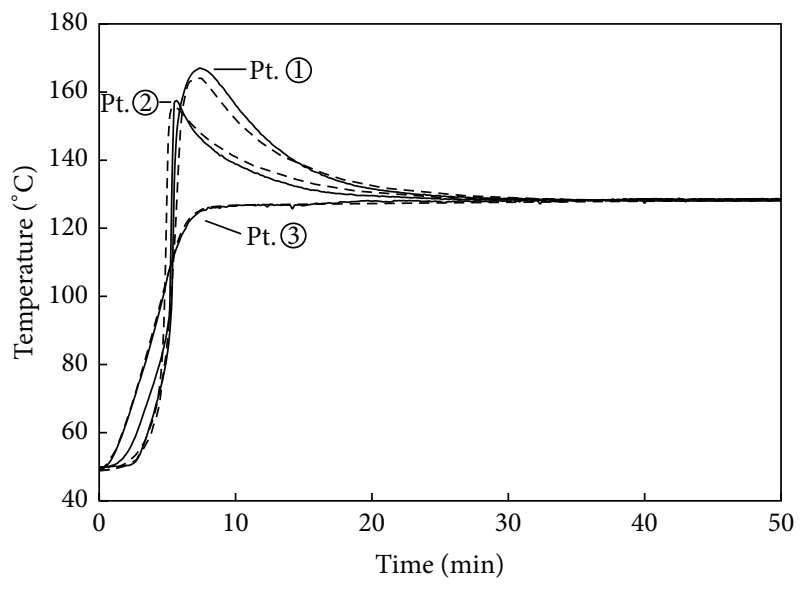

$$
\begin{aligned}
& \text { — Experiment } \\
& \text { - - FEA }
\end{aligned}
$$

(a)

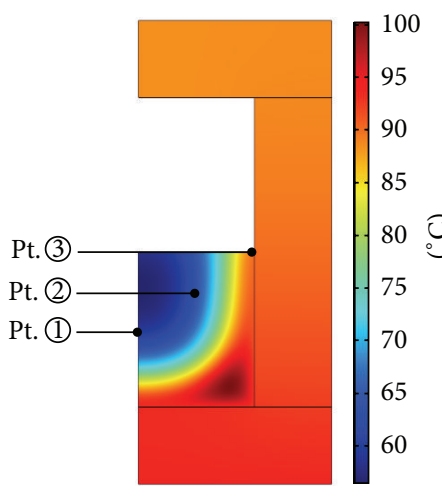

$5 \mathrm{~min}$

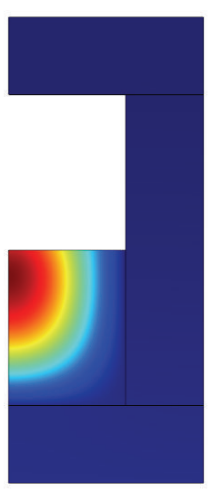

$10 \mathrm{~min}$

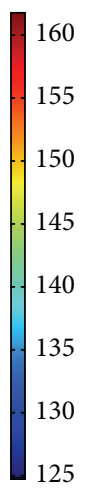

(b)

FiguRE 5: Comparison of the experimental data and simulation (points 1, 2, and 3). (a) Experiment and simulation. (b) Temperature contour (simulation).

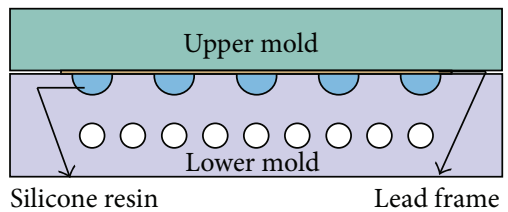

(a)

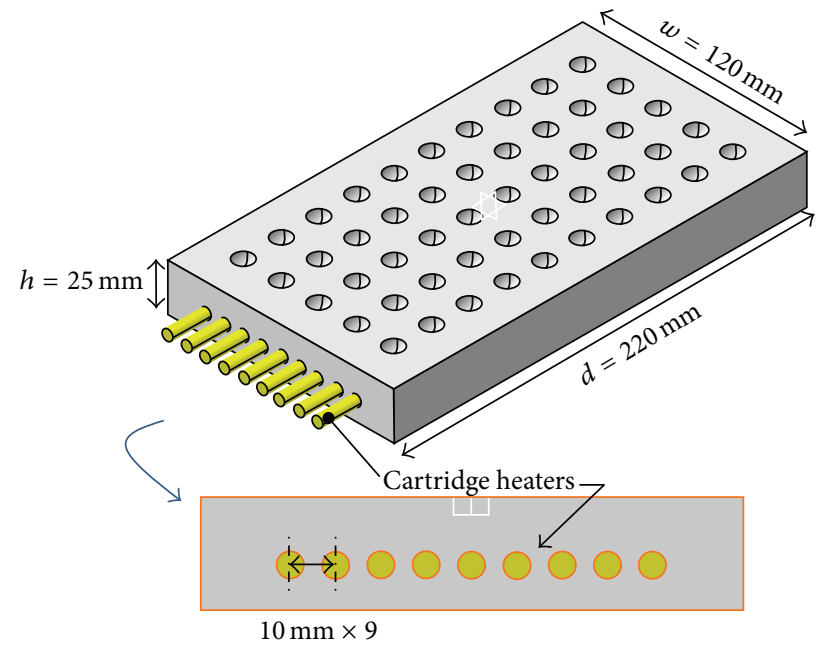

(b)

FIGURE 6: Analysis model for LED lens molding. (a) Layout of large area LED lens molding. (b) Lower mold specification for LED lens molding. 


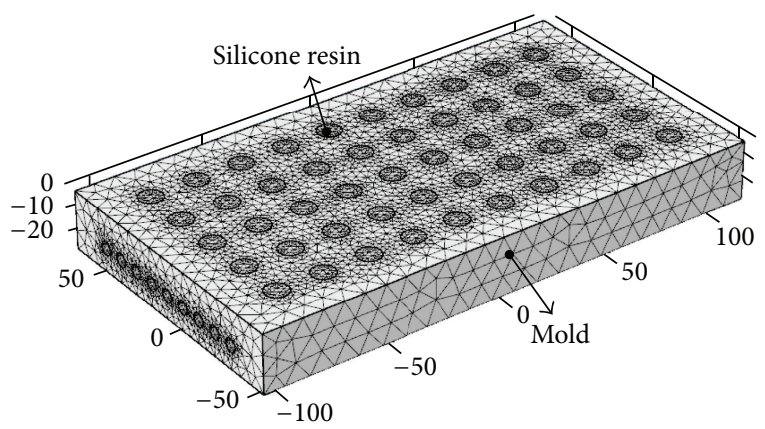

FIgURE 7: F.E. model for LED lens molding.

products [21]. Therefore, this uneven temperature distribution might adversely affect the degree of cure in the lens which may not be beneficial in producing LED products having even property.

Therefore, the location of heat source was changed to make the degree of cure uniform according to location as shown in Figure 9(a); that is, the gap between heaters was increased linearly from the center where a large amount of heat was received. Simulation results showed that silicone was uniformly cured according to location as shown in Figure 8. At this time, all reaction peaks were observed after $140 \mathrm{sec}$ and the temperature was in the range of $158.8^{\circ} \mathrm{C}-159.7^{\circ} \mathrm{C}$ with a much decreased temperature deviation of $0.9^{\circ} \mathrm{C}$.

\subsection{Reaction Peak Temperature and Cycle Time Reduction.} Abrupt temperature peak was generated while material was cured at an isothermal temperature of $130^{\circ} \mathrm{C}$ even if temperatures were the same everywhere. This abrupt temperature and degree of cure occurring during curing reaction greatly affected the mechanical properties of the final products [19]. Therefore, it is necessary to make a process wherein mold is heated from a low temperature to prevent this abrupt cure reaction. Figure 10 shows an isothermal simulation at $130^{\circ} \mathrm{C}$ and dynamic one-step heating at a rate of $10^{\circ} \mathrm{C} / \mathrm{min}$. The measurement point of silicone resin was at point 1 as shown in Figure 8(a), while mold temperature was measured from the center of the mold. There was almost no reaction peak in the dynamic heating. The curing process was almost completed by dynamic heating at around $919 \mathrm{sec}$. Though isothermal cure was quickly completed in around $381 \mathrm{sec}$, the process was introduced to prevent this excessive reaction peak and to reduce the cycle time since cure accompanied excessive reaction peak.

There is a step cure process to reduce reaction peak and to decrease cycle time; that is, by regulating dynamic heating and dwell time, abrupt exothermic reaction is prevented and uniform products are obtained [19, 21, 33-38]. Therefore, cure profile was introduced with a two-step heating rate and uniform temperature holding as shown in Figure 11. Further, optimization analysis was carried out to find an optimum cure condition to reduce cycle time and reaction peak. Here, $t$ is the cycle time (sec), $T$ is the cure temperature $\left({ }^{\circ} \mathrm{C}\right)$, and $Q$ is the heating rate $\left({ }^{\circ} \mathrm{C} / \mathrm{min}\right)$.
Optimum value $f$ as in (12) and constraints in (13) were set in order to obtain an optimum cycle; that is, reaction peak did not exceed $132^{\circ} \mathrm{C}$ and the total cycle time was set to a minimum, not exceeding 9 minutes and comprising a onestep cycle time as shown in Figure 10:

$$
\begin{aligned}
f_{\text {optimization }}=\min & \left(t_{\text {cycle time }}\right) \\
\text { subject to } & T_{\text {reaction peak }}<132^{\circ} \mathrm{C}, \\
& t_{\text {cycle time }} \\
& =\left(d t_{1}+d t_{2}+d t_{3}+d t_{4}\right)_{\alpha=1.0} \\
& <900 \sec (15 \mathrm{~min}) .
\end{aligned}
$$

4.2.1. Changes according to Dwell Temperature $\left(T_{2}\right)$. First of all, the changes according to dwell temperature $\left(T_{2}\right)$ were investigated because Song et al. [2] reported that one-step dwell temperature affected most of the changes. $T_{2}$ was set to $103^{\circ} \mathrm{C}, 113^{\circ} \mathrm{C}$, and $123^{\circ} \mathrm{C}$. One-step heating rate $\left(Q_{1}\right)$ was set to $30^{\circ} \mathrm{C} / \mathrm{min}$, while two-step heating rate $\left(Q_{2}\right)$ was set to $10^{\circ} \mathrm{C} / \mathrm{min}$. Simulation results are presented in Figure 12 and it was observed that as dwell temperature was increased, the reaction peak was also increased. Peaks were not observed at $103^{\circ} \mathrm{C}$ and $113^{\circ} \mathrm{C}$, while reaction peak at $145^{\circ} \mathrm{C}$ was observed under $T_{2}$ at $123^{\circ} \mathrm{C}$ condition. As far as degree of cure was concerned, cure was completed at $796 \mathrm{sec}$ for $T_{2}$ at $103^{\circ} \mathrm{C}$, at $716 \mathrm{sec}$ for $T_{2}$ at $113^{\circ} \mathrm{C}$, and at $632 \mathrm{sec}$ for $T_{2}$ at $123^{\circ} \mathrm{C}$, all of which were greatly reduced compared with cure by onestep (at $919 \mathrm{sec}$ ). Since temperature exceeded $123^{\circ} \mathrm{C}$ compared to the target reaction peak, it was clear that optimum dwell temperature $\left(T_{2}\right)$ was near $113^{\circ} \mathrm{C}$.

4.2.2. Changes according to Heating Rate $\left(Q_{1}\right)$. The heating rate $\left(Q_{1}\right)$ of one-step was adjusted to investigate the cure profile changes according to heating rate. Cure cycle time $\left(d t_{1}+d t_{2}\right)$ was set constant during the experiment. Figure 13 shows the changes of reaction peak according to heating rate. Reaction peak was not generated greatly even if heating rate was increased but it was shifted horizontally, making cycle time reduced. Therefore, one-step heating rate $\left(Q_{1}\right)$ was applied as an isothermal $\left(d t_{1}=0\right)$. However, cycle time was rather increased from $716 \mathrm{sec}$ to $725 \mathrm{sec}$. This might be because protracted dwell time led to a temperature drop lower than $130^{\circ} \mathrm{C}$ after reaction peak which hindered the cure process. Therefore, an optimum condition was added, with the temperature of silicone resin maintained higher than $130^{\circ} \mathrm{C}$ after reaction peak:

$$
\text { subject to } 130^{\circ} \mathrm{C} \leq T_{\text {after reaction peak }}<132^{\circ} \mathrm{C} \text {. }
$$

4.2.3. Changes according to Dwell Time $\left(d t_{2}\right)$. The reaction peak was observed while reducing dwell time $\left(d t_{2}\right)$ with reference to the experimental results in Section 4.2.2. Onestep heating rate $Q_{1}$ was applied as an isothermal condition and $Q_{2}$ was fixed at $10^{\circ} \mathrm{C} / \mathrm{min}$. Dwell time $\left(d t_{2}\right)$ was changed to $145 \mathrm{sec}$ and $115 \mathrm{sec}$ which were isothermal conditions as shown in Figure 14. At $145 \mathrm{sec}$ and $115 \mathrm{sec}$, reaction peaks 


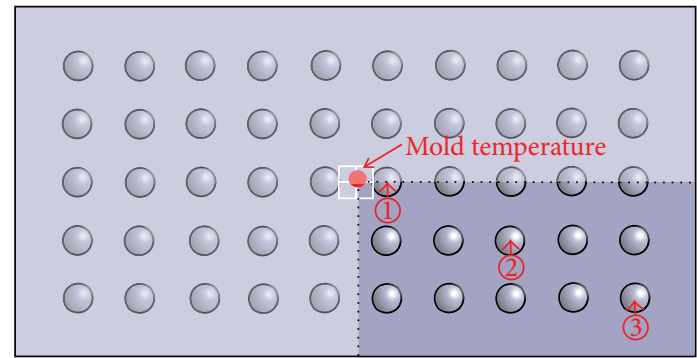

(a)



(b)

FIgURE 8: Temperature profile of large area LED lens molding. (a) Measuring points of silicone resin and mold temperature. (b) Temperature profile of silicone resin and mold.

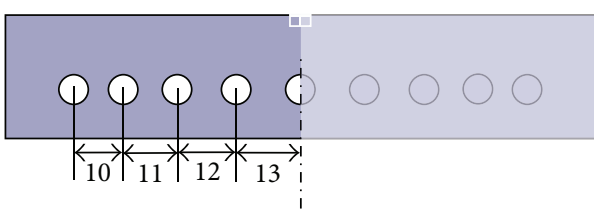

(a)

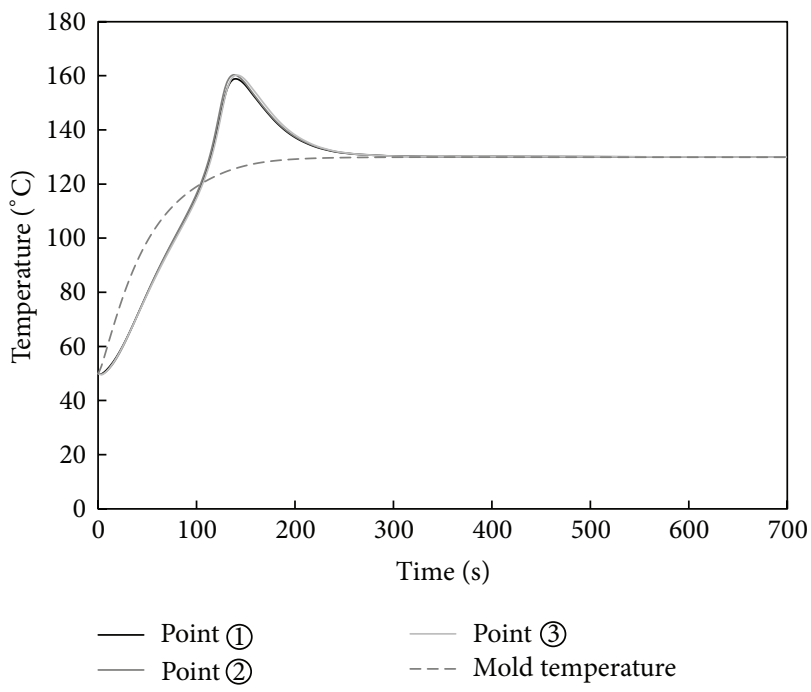

(b)

Figure 9: Temperature profile of silicone resin by heat source change: (a) optimized position of heat source for uniform heating and (b) optimized temperature profile of silicone resin and mold.

of $131.7^{\circ} \mathrm{C}$ and $136.2^{\circ} \mathrm{C}$ were observed. As dwell time $\left(d t_{2}\right)$ was reduced, reaction peak gradually increased. Therefore, optimum cure process which reduced cure cycle was drawn within the reaction peak of $132^{\circ} \mathrm{C}$. Parameter values with optimum simulation were arranged as shown in Table 3.

Figure 15 shows comparison results between one-step heating rate simulation at $10^{\circ} \mathrm{C} / \mathrm{min}$ as in Figure 10 and the optimum simulation results. As can be seen from the figure, temperature increased without reaction peak but cycle time was greatly reduced. Optimum cure time was reduced from $919 \mathrm{sec}$ to $649 \mathrm{sec}$ which ultimately reduced cycle time by around $29 \%$.

\section{Conclusions}

In this study, a three-dimensional heat transfer-cure analysis was performed for the large area compression molding process for forming lens and encapsulants simultaneously. A dynamic cure kinetics model for the silicone resin was proposed and the analysis result was validated through experiments with a simple-shaped object. The position of heat source was optimized by carrying out simulation using a large area mold having $10 \times 5$ cavities to reduce temperature deviation between each cavity. A two-step cure cycle was also constructed to reduce excessive reaction peak at the initial 
TABLE 3: Optimized parameters for cure cycle reduction.

\begin{tabular}{cccccccccc}
\hline$T_{1}$ & $T_{2}$ & $T_{3}$ & $Q_{1}$ & $Q_{2}$ & $\mathrm{dt}_{1}$ & $\mathrm{dt}_{2} \mathrm{~s}$ & $\mathrm{dt}_{3}$ & Reaction peak & $f_{\text {optimization }}=\min \left(t_{\text {cycle time }}\right)$ \\
\hline 50 & 113 & 130 & ISO & 10 & 0 & 145 & 102 & $131.7^{\circ} \mathrm{C}$ & $649 \mathrm{sec}$ \\
\hline
\end{tabular}

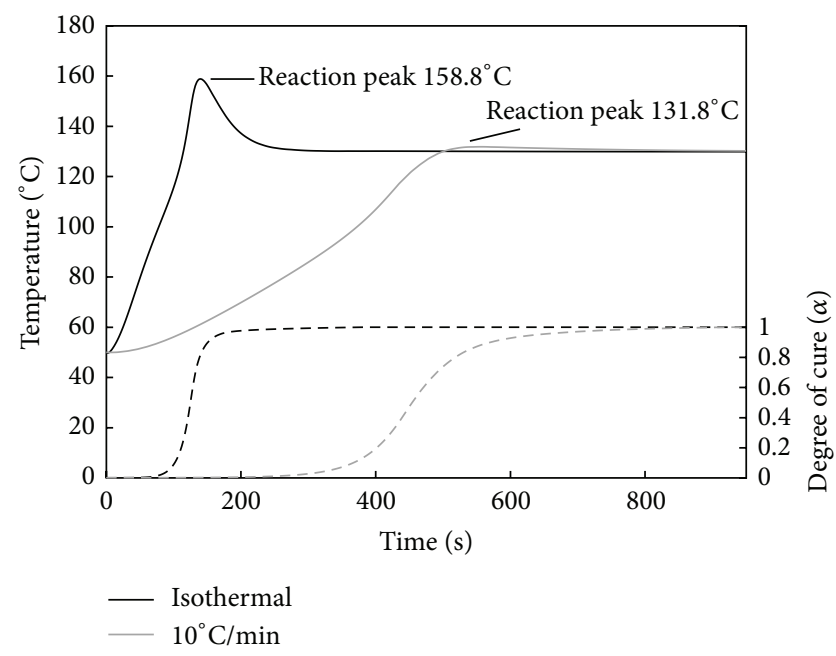

Figure 10: Comparison of cure profile between one-step and isothermal curing.

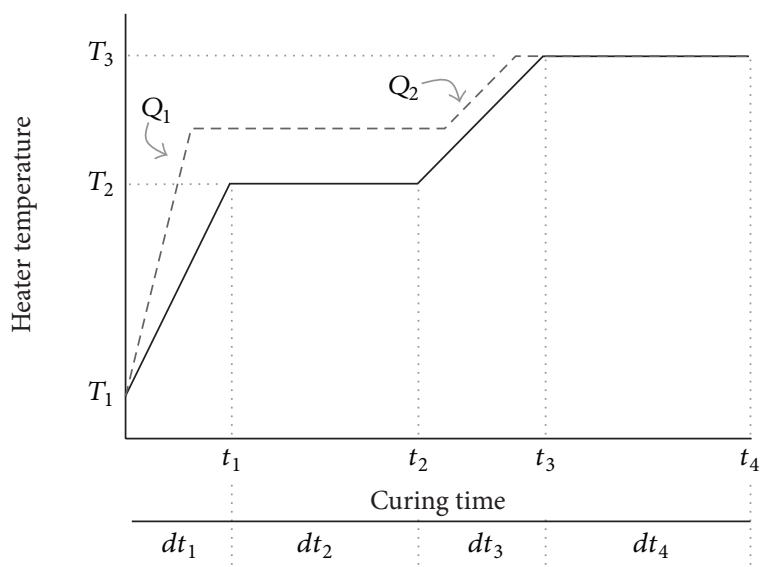

FIGURE 11: Schematic diagram of the two-step curing process.

stage and cycle time. An optimum cure cycle that could reduce cycle time by more than $29 \%$, compared to one-step cure, by adjusting dwell temperature, heating rate, and dwell time, was then proposed.

It was confirmed that optimization could be achieved for the large area LED molding process through finite element technique and experiment. Cure process can be drawn for optimum LED molding by investigating material properties even when silicone resin was adopted as material and by performing finite element analysis for the various cure processes (cure temperature, cure time, and heating mold changes) based on the experiment.

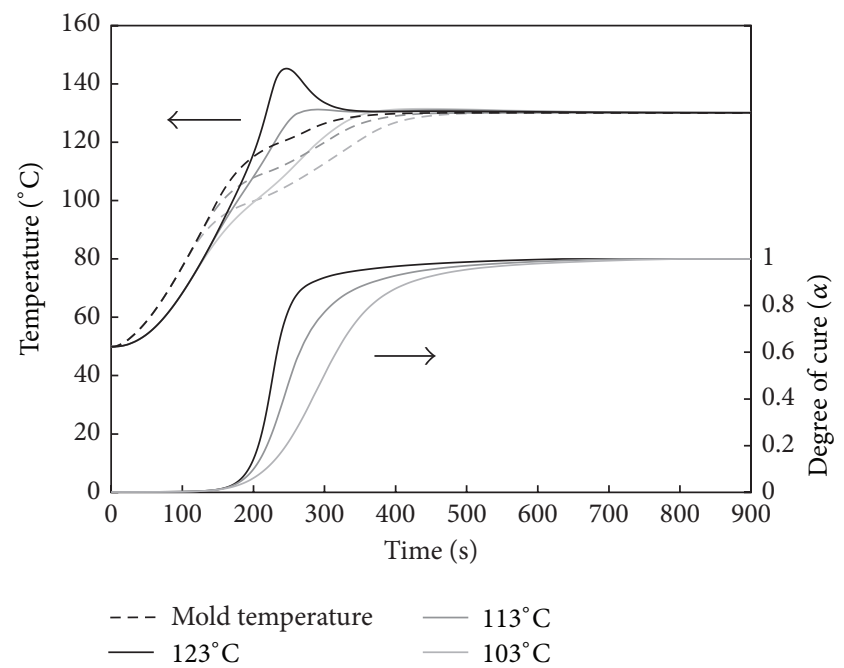

FIGURE 12: Cure profile of silicone resin increasing dwell temperature $\left(T_{2}\right)$.

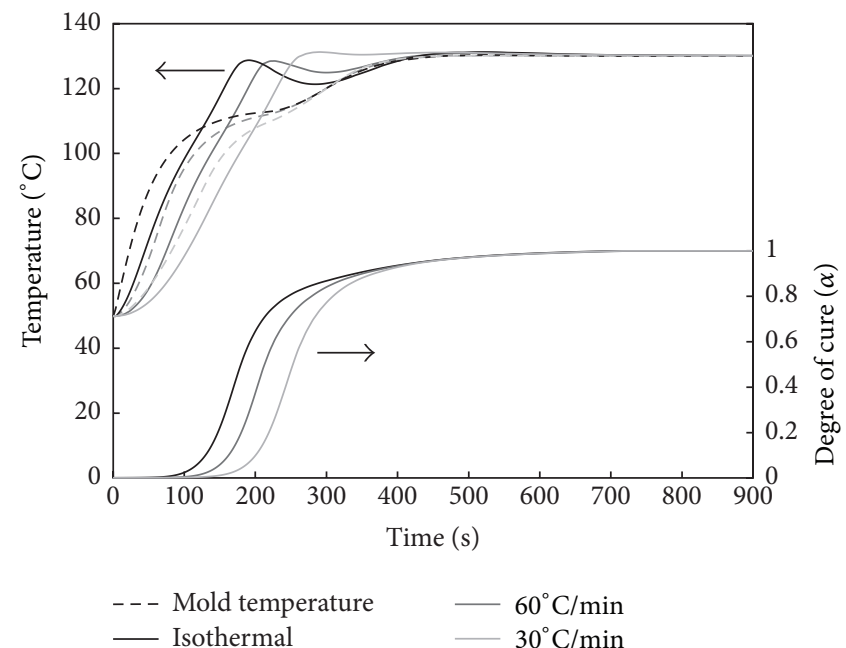

FIGURE 13: Cure profile of silicone resin increasing heating rate $\left(Q_{1}\right)$.

\section{Conflict of Interests}

The authors declare that there is no conflict of interests regarding the publication of this paper.

\section{Acknowledgments}

This study was supported by a grant from the Fundamental R\&D Program, "The Development of LED Chip/Package Phosphor Conformal Coating System for White LED" and "Development of Rapid Compression Molding Technology 


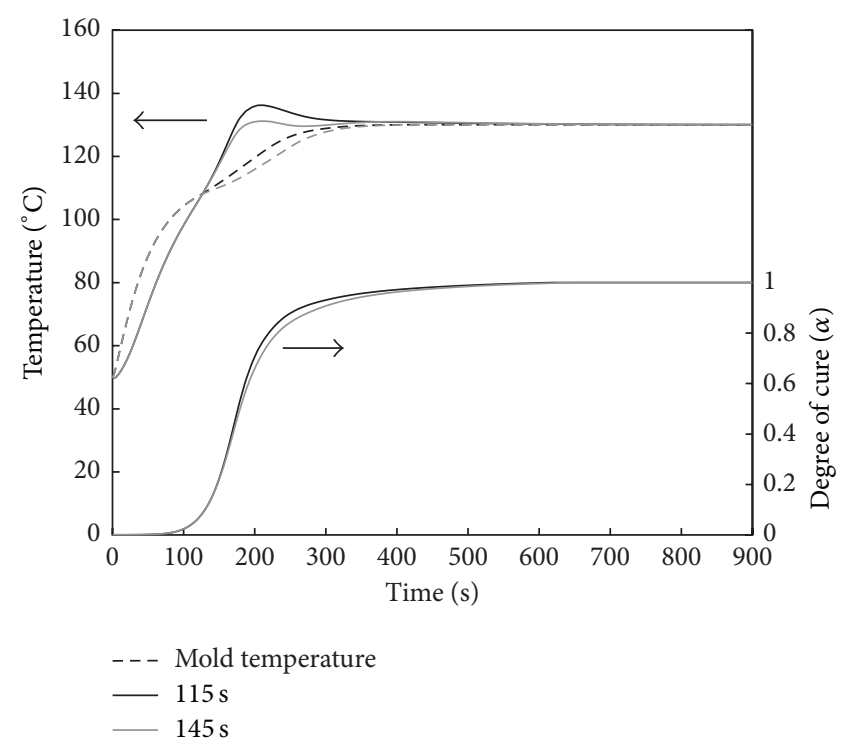

FIGURE 14: Cure profile of silicone resin decreasing dwell time $\left(d t_{2}\right)$.

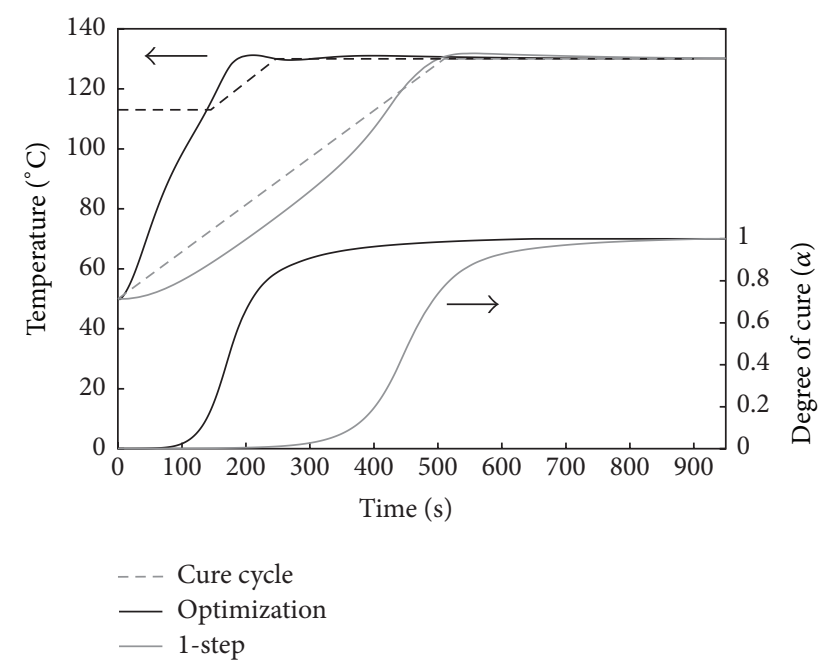

FIGURE 15: Comparison of cure profile between optimized and onestep curing process.

with Continuous Carbon Fiber Reinforced Composite for the Car Weight-Lightning" funded by the Ministry of Trade, Industry \& Energy, Republic of Korea, and Basic Science Research Program through the National Research Foundation of Korea (NRF) funded by the Ministry of Science, ICT \& Future Planning (MSIP) (no. 2007-0056094).

\section{References}

[1] D. Lu and C. P. Wong, Materials for Advanced Packaging, Springer, 2008.

[2] M. J. Song, K. H. Kim, G. S. Yoon, H. P. Park, and H. K. Kim, "An optimal cure process to minimize residual void and optical birefringence for a LED silicone encapsulant," Materials, vol. 7, pp. 4088-4104, 2014.
[3] S.-Y. Lee and G. S. Springer, "Filament winding cylinders. I. Process model," Journal of Composite Materials, vol. 24, no. 12, pp. 1270-1298, 1990.

[4] E. P. Calius, S.-Y. Lee, and G. S. Springer, "Filament winding cylinders: II. Validation of the process model," Journal of Composite Materials, vol. 24, no. 12, pp. 1299-1343, 1990.

[5] S. Y. Lee and G. S. Springer, "Filament winding cylinders: III selection of the process variables," Journal of Composite Materials, vol. 24, pp. 1270-1298, 1990.

[6] A. C. Loos and G. S. Springer, "Curing of epoxy matrix composites," Journal of Composite Materials, vol. 17, no. 2, pp. 135-169, 1983.

[7] C. Kim, H. Teng, C. L. Tucker III, and S. R. White, "Continuous curing process for thermoset polymer composites. Part 1: modeling and demonstration," Journal of Composite Materials, vol. 29, no. 9, pp. 1222-1253, 1995.

[8] T. A. Bogetti and J. W. Gillespie, "Two-dimensional cure simulation of thick thermosetting composites," Journal of Composite Materials, vol. 25, no. 3, pp. 239-273, 1991.

[9] Z.-S. Guo, S. Du, and B. Zhang, "Temperature distribution of thick thermoset composites," Modelling and Simulation in Materials Science and Engineering, vol. 12, no. 3, pp. 443-452, 2004.

[10] A. Cheung, Y. Yu, and K. Pochiraju, “Three-dimensional finite element simulation of curing of polymer composites," Finite Elements in Analysis and Design, vol. 40, no. 8, pp. 895-912, 2004.

[11] M. Hojjati and S. V. Hoa, "Curing simulation of thick thermosetting composites," Composites Manufacturing, vol. 5, no. 3, pp. 159-169, 1994.

[12] D. Rouison, M. Sain, and M. Couturier, "Resin transfer molding of natural fiber reinforced composites: cure simulation," Composites Science and Technology, vol. 64, no. 5, pp. 629-644, 2004.

[13] K. Kasza, L. Matysiak, and L. Malinowski, "Method to describe curing in large epoxy samples," Advances in Polymer Technology, vol. 28, no. 4, pp. 267-275, 2009.

[14] L. Liu, S. Yi, L. S. Ong, and K. S. Chian, "Finite element analysis for microwave cure of underfill in flip chip packaging," Thin Solid Films, vol. 462-463, pp. 436-445, 2004.

[15] T. Behzad and M. Sain, "Finite element modeling of polymer curing in natural fiber reinforced composites," Composites Science and Technology, vol. 67, no. 7-8, pp. 1666-1673, 2007.

[16] A. Shojaei, S. R. Ghaffarian, and S. M. H. Karimian, "Threedimensional process cycle simulation of composite parts manufactured by resin transfer molding," Composite Structures, vol. 65, no. 3-4, pp. 381-390, 2004.

[17] S. C. Joshi, X. L. Liu, and Y. C. Lam, "A numerical approach to the modeling of polymer curing in fibre-reinforced composites," Composites Science and Technology, vol. 59, no. 7, pp. 1003-1013, 1999.

[18] R. Sekula, P. Saj, T. Nowak et al., "3-D modeling reactive molding processes: from tool development to industrial application," Advances in Polymer Technology, vol. 22, no. 1, pp. 42-55, 2003.

[19] S. Yi, H. H. Hilton, and M. F. Ahmad, "A finite element approach for cure simulation of thermosetting matrix composites," Computers and Structures, vol. 64, no. 1-4, pp. 383-388, 1997.

[20] H. C. Park, N. S. Goo, K. J. Min, and K. J. Yoon, "Threedimensional cure simulation of composite structures by the finite element method," Composite Structures, vol. 62, no. 1, pp. 51-57, 2003. 
[21] M. A. Choi, M. H. Lee, J. Chang, and S. J. Lee, "Threedimensional simulations of the curing step in the resin transfer molding process," Polymer Composites, vol. 20, no. 4, pp. 543$552,1999$.

[22] J. Zhang, Y. C. Xu, and P. Huang, "Effect of cure cycle on curing process and hardness for epoxy resin," Express Polymer Letters, vol. 3, no. 9, pp. 534-541, 2009.

[23] S. Teplinsky and E. M. Gutman, "Computer simulation of process induced stress and strain development during cure of thicksection thermosetting composites," Computational Materials Science, vol. 6, no. 1, pp. 71-76, 1996.

[24] M. R. Kamal and S. Sourour, "Kinetics and thermal characterization of thermoset cure," Polymer Engineering \& Science, vol. 13, pp. 59-64, 1973.

[25] M.-K. Um, I. M. Daniel, and B.-S. Hwang, "A study of cure kinetics by the use of dynamic differential scanning calorimetry," Composites Science and Technology, vol. 62, no. 1, pp. 29-40, 2002.

[26] G. Wisanrakkit and J. K. Gillham, "The glass transition temperature $\left(T_{g}\right)$ as an index of chemical conversion for a high$T_{g}$ amine/epoxy system: chemical and diffusion-controlled reaction kinetics," Journal of Applied Polymer Science, vol. 41, no. 11-12, pp. 2885-2929, 1990.

[27] F. Hernandez-Sanchez and R. Vera-Graziano, "Determination of the kinetic parameters for the polymerization of a polyurethane using an improved method of differential scanning calorimetry," Journal of Applied Polymer Science, vol. 46, no. 4, pp. 571-580, 1992.

[28] S. Vyazovkin, "A unified approach to kinetic processing of nonisothermal data," International Journal of Chemical Kinetics, vol. 28, no. 2, pp. 95-101, 1996.

[29] A. Atarsia and R. Boukhili, "Relationship between isothermal and dynamic cure of thermaosets via the isoconversion representation," Polymer Engineering and Science, vol. 40, no. 3, pp. 607-620, 2000

[30] D. Lu and C. P. Wong, "Effects of shrinkage on conductivity of isotropic conductive adhesives," International Journal of Adhesion and Adhesives, vol. 20, no. 3, pp. 189-193, 2000.

[31] T. A. Bogetti and J. W. Gillespie Jr., "Process-induced stress and deformation in thick-section thermoset composite laminates," Journal of Composite Materials, vol. 26, no. 5, pp. 626-660, 1992.

[32] J.-L. Bailleul, V. Sobotka, D. Delaunay, and Y. Jarny, "Inverse algorithm for optimal processing of composite materials," Composites Part A: Applied Science and Manufacturing, vol. 34, no. 8, pp. 695-708, 2003.

[33] M. Li and C. L. Tucker III, "Optimal curing for thermoset matrix composites: thermochemical and consolidation considerations," Polymer Composites, vol. 23, no. 5, pp. 739-757, 2002.

[34] E. Ruiz and F. Trochu, "Comprehensive thermal optimization of liquid composite molding to reduce cycle time and processing stresses," Polymer Composites, vol. 26, no. 2, pp. 209-230, 2005.

[35] S. R. White and H. T. Hahn, "Cure cycle optimization for the reduction of processing-induced residual stresses in composite materials," Journal of Composite Materials, vol. 27, no. 14, pp. 1352-1378, 1993.

[36] A. K. Gopal, S. Adali, and V. E. Verijenko, "Optimal temperature profiles for minimum residual stress in the cure process of polymer composites," Composite Structures, vol. 48, no. 1, pp. 99-106, 2000.

[37] E. Ruiz and F. Trochu, "Numerical analysis of cure temperature and internal stresses in thin and thick RTM parts," Composites
Part A: Applied Science and Manufacturing, vol. 36, no. 6, pp. 806-826, 2005.

[38] N. Rai and R. Pitchumani, "Optimal cure cycles for the fabrication of thermosetting-matrix composites," Polymer Composites, vol. 18, no. 4, pp. 566-581, 1997. 

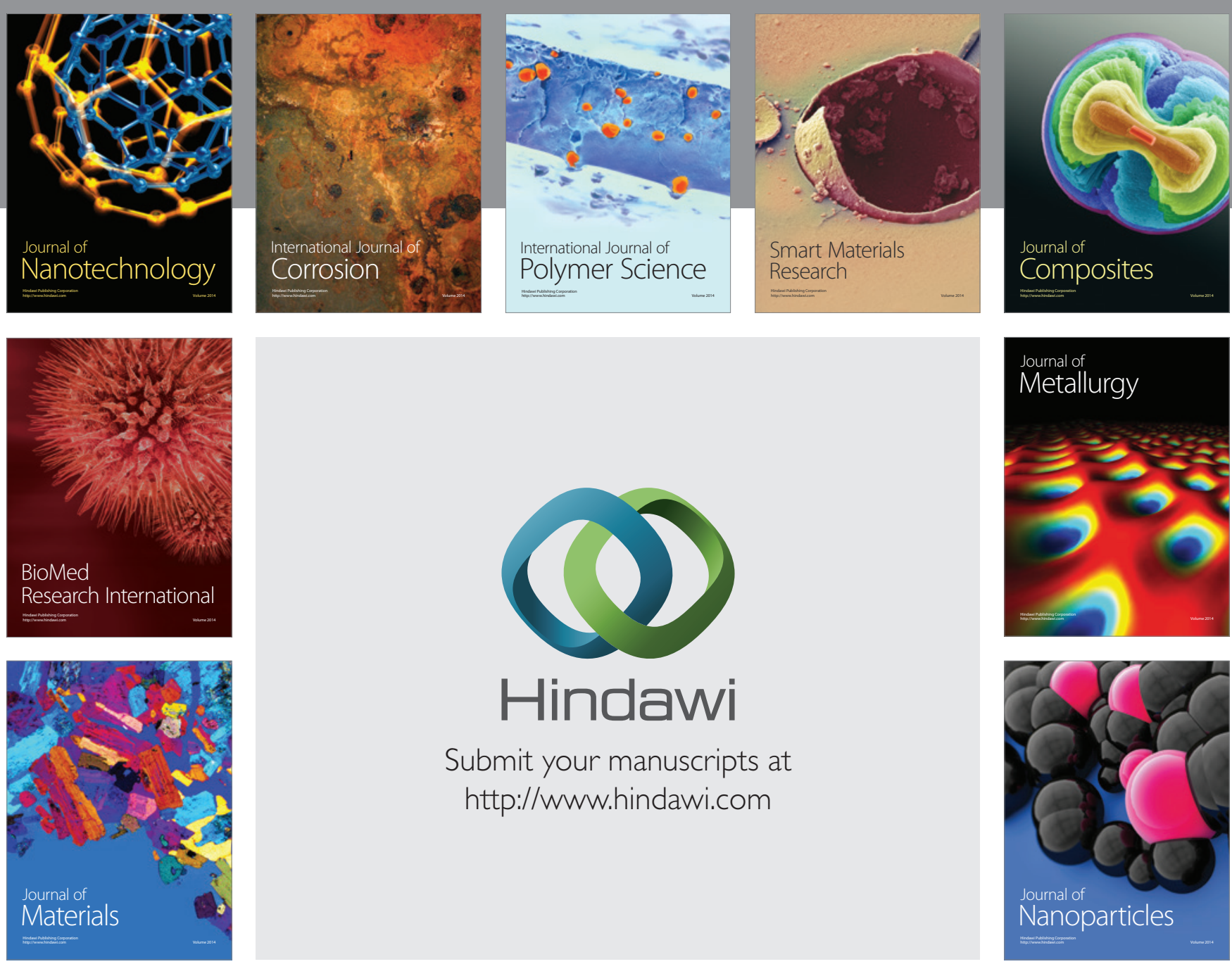

Submit your manuscripts at http://www.hindawi.com
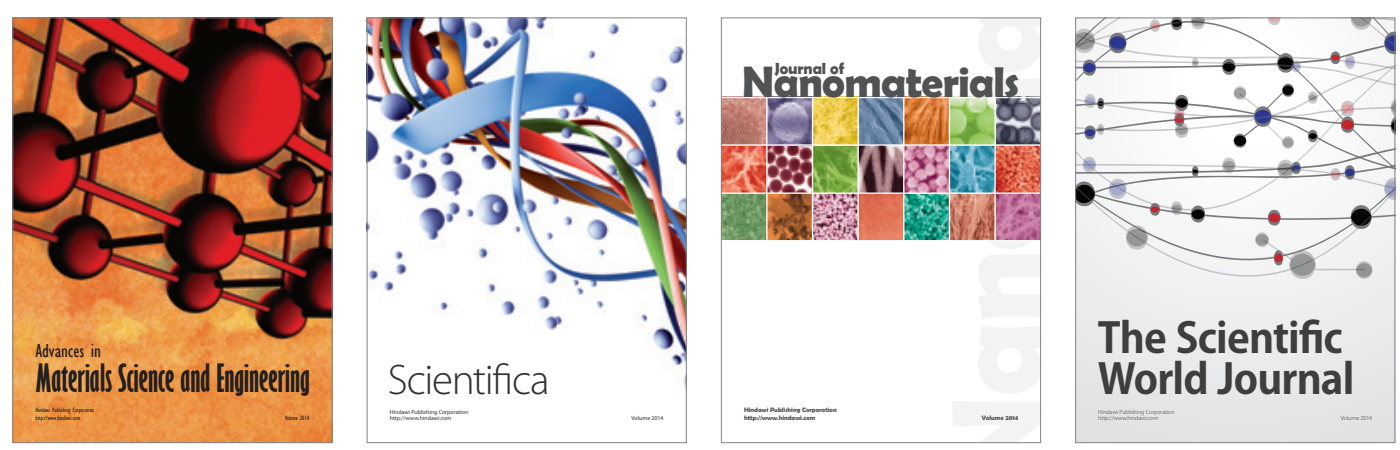

\section{The Scientific World Journal}
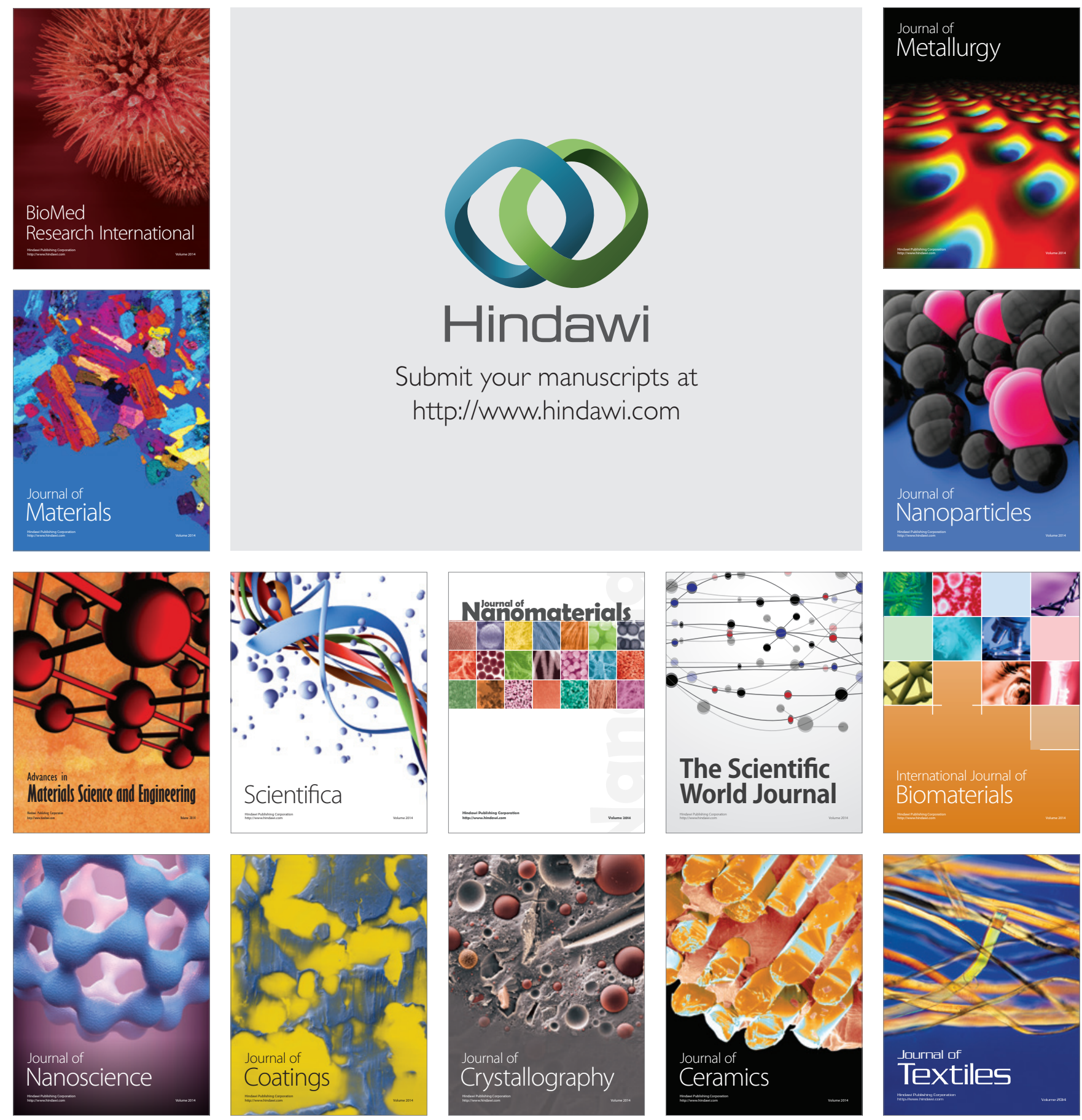